\title{
Assessing thermodynamic models and introducing novel method for prediction of methane hydrate formation
}

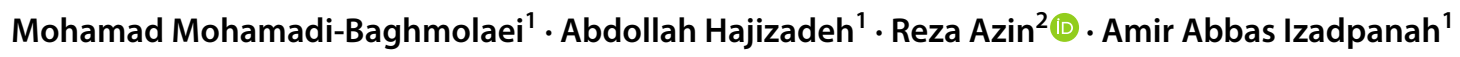

Received: 10 August 2017 / Accepted: 26 November 2017 / Published online: 12 December 2017

(c) The Author(s) 2017. This article is an open access publication

\begin{abstract}
Transmission of natural gas with methane as the main constituent has been a subject of interest to industrial companies. Predicting hydrate formation conditions is important to prevent formation of methane hydrate in gas pipeline. Also, attention has been taken to account for capture and storage of pure methane. In this paper, a comprehensive comparison is performed between empirical correlations and different equation of state in van der Waals Platteeuw (VdW-P) thermodynamic model to determine the most accurate method of hydrate formation condition of methane. In addition, a novel, simple and accurate correlation is developed to predict methane hydrate formation temperature using genetic programming. Error analysis on a wide range of experimental data indicates that the new proposed correlation is superior over existing correlations and all VdW-P models with $R^{2}=0.999$.
\end{abstract}

Keywords Empirical correlation $\cdot$ VdW-P $\cdot$ Hydrate formation $\cdot$ Methane $\cdot$ Genetic programming

\section{List of symbols}

\begin{tabular}{|c|c|}
\hline$A, B$ & Fitted constants (K/atm, $K)$ \\
\hline$a$ & Activity \\
\hline$C$ & Langmuir constant (1/atm) \\
\hline$C_{P}$ & Specific heat capacity, (cal/mol K) \\
\hline$f$ & Fugacity (bar) \\
\hline$M$ & Types of cavity \\
\hline$N$ & $\begin{array}{l}\text { The number of types of cavities in crystalline } \\
\text { hydrate lattice }\end{array}$ \\
\hline$N H$ & $\begin{array}{l}\text { The number of gas type molecules which can } \\
\text { entry the hydrate phase and fill the cavities }\end{array}$ \\
\hline , & $\begin{array}{l}\text { The number of cavities of type } i \text { per water mol- } \\
\text { ecule in the lattice }\end{array}$ \\
\hline & Molar volume $\left(\mathrm{cm}^{3} / \mathrm{mol}\right)$ \\
\hline & Chemical potential $(\mathrm{J} / \mathrm{mol})$ \\
\hline & Fugacity coefficient \\
\hline
\end{tabular}

Reza Azin

reza.azin@pgu.ac.ir

1 Department of Chemical Engineering, Faculty of Petroleum, Gas and Petrochemical Engineering, Persian Gulf University, Bushehr, Iran

2 Department of Petroleum Engineering, Faculty of Petroleum, Gas and Petrochemical Engineering, Persian Gulf University, Bushehr, Iran

\author{
Abbreviations \\ HFP Hydrate formation pressure \\ HFT Hydrate formation temperature \\ AARE Average absolute error \\ $R^{2} \quad$ Squared correlation coefficient \\ RMSE Root-mean-squared error \\ RSS Residual sum of square \\ Subscripts \\ $w \quad$ Water \\ g Gas \\ $j, i \quad$ Components $j, i$ \\ jm Component $m$ in cavity $j$

\section{Superscripts} \\ $V \quad$ Vapor phase \\ $L \quad$ Liquid phase \\ $H \quad$ Hydrate phase \\ $\beta \quad$ Virtual phase \\ $\beta-L \quad$ Difference between crystalline hydrate lattice and \\ liquid \\ $\beta-H \quad$ Difference between crystalline hydrate lattice and \\ hydrate
}




\section{Introduction}

The gas hydrates are pseudo-ice structured compounds which consist of water molecules and natural gas components. The natural gas components act as guest trapped in cage-like structure formed by water (Sloan and Koh 2007; Bahadori and Vuthaluru 2009). Generally, hydrate is generated at specific low temperature and high pressure which are affected by gas composition. Hydrate formation usually causes unfavorable effects such as obstruction in pipelines, gas tubing wells and in surface facilities (Elgibaly and Elkamel 1998). $\mathrm{C}_{2}{ }^{+}$recovery from natural gas is an economic process through which methane with high purity is separated from other hydrocarbons, and is subject to hydrate formation in presence of water. Hence, any effort which facilitates prevention of unsolicited phenomenon such as methane hydrate formation in gas transmission pipeline should be taken into consideration (Koh et al. 2002). High energy demand persuades countries like China, Japan, India and South Korea to explore and exploit methane hydrate resources (Collett 2002; Vedachalam et al. 2015; Konno et al. 2016). It was understood that methane hydrate-bearing sandy sediments are found in the Japan, South Korea, India and USA (Ruppel et al. 2008; Ryu et al. 2013; Collett et al. 2014; Fujii et al. 2015). Several researchers tried to explore different aspects of methane hydrate formation conditions. Zhong et al. investigated separating methane from a coal mine methane gas using gas hydrate crystallization method (2016). This was due to large gas storage capacity of methane hydrate and finding average formation conditions. Their proposed method was promising for separation of gas mixtures. Another illustration is that of Zhong et al. (2015) who used gas hydrate formation for $\mathrm{CO}_{2}$ removal from a simulated shale gas. Moreover, methane hydrate formation as a huge source of energy was the aim of study indifferent researches especially to evaluate enhancement of methane hydrate growth and its density. As an example, Ganji et al. used a surfactant to decrease surface tension of water. Results of their study showed that methane hydrate formation rate and storage capacity increased effectively (Ganji et al. 2007). Several studies focus on the rate of methane hydrate formation in presence of different chemicals and porous materials (Liang et al. 2005, 2009a, b; Yan et al. 2005; Ganji et al. 2007; Park and Kim 2010; Babu et al. 2013; Chari et al. 2013; Pasieka et al. 2013; Lim et al. 2014, Siangsai et al. 2014, 2015).

Studies of hydrate formation prediction are presented in two general categories, thermodynamic models and empirical correlations. In addition, use of intelligent models is extended recently for prediction of physical properties of energy sources (Mohamadi-Baghmolaei et al. 2014, 2015).
Mathematical-based equations and thermodynamic relations are proposed for use in simulation process and program code where the relationship between input and output is pretty clear. Common thermodynamic models for hydrate formation are $K$ value method and van der Waals Platteeuw (Wilcox et al. 1941; Van der Waals and Platteeuw 2007). The first method is developed based on vapor-solid equilibrium constants for prediction of hydrate formation condition, while the second is based on statistical thermodynamic approach. The main drawback of thermodynamic models is their weak ability in prediction of high and low pressure and temperature. Also, thermodynamic models are complicated to be programmed and applied (Garapati and Anderson 2014). Application of thermodynamic models as function of equation of state including several components is considerably time taking process as the inter-molecular interaction and proper mixing rules should be estimated through trial and error process (Mohamadi-Baghmolaei et al. 2014, 2016a). In the case of empirical correlations, the input parameters include temperature, pressure and gas gravity. These methods are useful for rapid estimation of the hydrate formation conditions. Moreover, less input data make them easy to use for industrial and practical purposes (Carroll 2014). For instance, Hammerschmidt presented a simple empirical correlation for hydrate formation which was independent of gas gravity (1934). This correlation shown in Eq. (1) is function of pressure (psi) and results the temperature $\left({ }^{\circ} \mathrm{F}\right)$ of hydrate formation. The simplicity of Hammerschmidt $(\mathrm{HSCH})$ correlation may cause deviation from experimental data.

$T=8.9 P^{0.285}$

Another example is Holder et al.'s (1988) correlation developed for predicting hydrate formation pressure which was simple and easy to use. Their correlation depends on two coefficients which are function of temperature range for each gas. These coefficients can be determined by curve fitting on experimental data.

$P=\exp \left(38.9803+\frac{-8533.80}{T}\right)$

Some empirical correlations contain large number of coefficients in their equations. For example, Kobayashi et al. (1987) proposed their correlation with fifteen coefficients. Other example in the same category is the presented correlation by Amin et al. (2015) which was developed based on leverage approach or Ghiasi (2012) who offered a correlation as a function of molecular weight and pressure to predict hydrate formation temperature (HFT). Ghiasi developed his correlation for prediction of hydrate formation temperature (HFT) (K) of sweet natural gases. The correlation depends on pressure $(\mathrm{kPa})$ and molecular weight $\left(M_{\mathrm{w}}\right)$. 
$T=A_{0}+A_{1} M_{\mathrm{w}}+A_{1} M_{\mathrm{w}}^{2}+A_{4}(\ln P)^{2}+A_{5} M_{\mathrm{w}} \ln P$

The coefficients of Eq. (3) are reported by Ghiasi (2012).

There are other correlations published in the literature which are tested in this paper. Details of these correlations are given in "Empirical correlations" appendix section.

In the current study, a comprehensive comparison is performed between empirical correlations and van der Waals Platteeuw (VdW-P) model. Application of VdW-P EOS is described for fugacity calculation. To do this, seven equations of state (EOS) including Virial, van der Waals (VdW), Redlich-Kwong (RK), Soave-Redlich-Kwong (SRK), Peng-Robinson (PR), Tsai-Jan (TJ) and Patel-Teja (PT) (Van der Waals 1873; Redlich and Kwong 1949; Soave 1972; Peng and Robinson 1976; Patel and Teja 1982; Tsai and Jan 1990; Prausnitz et al. 1998) are employed in VdW-P model to find an accurate method for predicting hydrate formation pressure (HFP) and HFT in temperature range of 259.1-320.1 (K). The accuracy of each model is validated using pure methane hydrate formation experimental data of temperature and pressure. Finally, new empirical correlation is developed for HFT of pure methane.

\section{Van der Waals Platteeuw model}

The VdW-P thermodynamic model which was proposed for hydrate formation conditions. This model is based on the following assumptions (Chen and Guo 1996):

1. Each cavity should contain at most one guest (gas) molecule.

2. The ideal gas partition function is applicable to guest molecules.

3. The interaction between guest and water molecules can be described by a pair potential function, and the cavity can be treated as perfectly spherical.

4. Guest-guest molecule interactions are neglected.

5. There is no interaction between guest molecules in different cavities, and the guest molecules interact only with the nearest neighboring water molecules.

6. The free energy contribution of water molecules is independent of the modes of occupancy of dissolved guest molecules.

Thermodynamic equilibrium suggests that chemical potentials of each component in liquid, solid (hydrate) and vapor $\left(L_{\mathrm{w}}-H-V\right)$ should be equal. This results in equality of fugacities which is the condition of equilibrium state. The fugacity and chemical potential of each term are denoted by $f$ (bar) and $\mu(\mathrm{J} / \mathrm{mol})$, respectively.

$\mu_{\mathrm{g}}^{L}(P, T)=\mu_{\mathrm{g}}^{V}(P, T)=\mu_{\mathrm{g}}^{H}(P, T)$
$\mu_{\mathrm{w}}^{L}(P, T)=\mu_{\mathrm{w}}^{V}(P, T)=\mu_{\mathrm{w}}^{H}(P, T)$

The chemical potential difference between hydrate and virtual phase $(\beta)$ is:

$\mu_{\mathrm{w}}^{\beta-H}(P, T)=\mu_{\mathrm{w}}^{\beta}(P, T)-\mu_{\mathrm{w}}^{H}(P, T)$

The potential difference of Eq. 3 is calculated using a statistical relation developed for gas hydrate (Van der Waals and Platteeuw 2007). It was assumed that the solid phase can be modeled by inspiring from the Langmuir gas adsorption model.

$\mu_{\mathrm{w}}^{\beta-H}(P, T)=R T \sum_{m=1}^{N} v_{m} \ln \left(1+\sum_{j=1}^{N H} C_{j m} f_{j}^{v}\right)$

where $R, T, \nu, C$ and $f$ are universal gas constant, temperature, number of type- $m$ cavities per water molecule in the lattice, the Langmuir constant and pure fugacity of component $j$. The number of types of cavities in crystalline hydrate lattice, types of cavity and number of gas type molecules which can enter the hydrate phase and fill the cavities are $N$, $m$ and $N H$, respectively.

The Langmuir constant can be calculated using LennardJones and Devonshire cell theory (1939) or empirical correlation proposed by Parrish and Prausnitz (1972).

$C_{j m}=\frac{A_{j m}}{T} \exp \left(\frac{B_{j m}}{T}\right)$

This correlation is fitted for temperature range of $260-300 \mathrm{~K}$.

Constants $A$ and $B$ of the current work are given in Table 1.

A proper EOS should be hired to obtain fugacity of component $\mathrm{j}$ in gas phase, Eq. (9). The applied EOS in the current study is introduced in "Equation of state" section.

$f_{j}^{v}=\emptyset_{j}^{v}(P, T, y, \mathrm{EOS}) \times P \times y_{j}$

The chemical potential difference of water and virtual phase is:

$\frac{\Delta \mu_{\mathrm{w}}^{\beta-L}}{R T}=\frac{\Delta \mu_{\mathrm{w}}^{0}}{R T_{0}}-\int_{T_{0}}^{T} \frac{\Delta h_{\mathrm{w}}^{\beta-L}}{R T^{2}} \mathrm{~d} T+\int_{P_{0}}^{P} \frac{\Delta v_{\mathrm{w}}^{\beta-L}}{R T} \mathrm{~d} P-\ln a_{\mathrm{w}}$

The molar enthalpy difference can be determined as:

$\Delta h_{\mathrm{w}}^{\beta-L}=\Delta h_{\mathrm{w}}^{0, \beta-L}+\int_{T_{0}}^{T} \Delta C_{P} \mathrm{~d} T$

Table 1 Coefficients of Langmuir constant

\begin{tabular}{lll}
\hline & $A \times \mathrm{e}+3(\mathrm{~K} / \mathrm{atm})$ & $B$ \\
\hline Small cavity & 0.7228 & 3187 \\
Large cavity & 23.35 & 2653 \\
\hline
\end{tabular}


Table 2 Thermodynamic parameters of VdW-P

\begin{tabular}{lllll}
\hline Properties & $\alpha^{\prime}$ & $\begin{array}{l}\Delta C_{P}^{0}(\mathrm{cal} / \\
\mathrm{mol} \mathrm{K})\end{array}$ & $\begin{array}{l}\Delta h_{\mathrm{w}}^{0, \beta-L}(\mathrm{cal} / \\
\mathrm{mol})\end{array}$ & $\begin{array}{l}\Delta v_{\mathrm{w}}^{0, \beta-L}\left(\mathrm{~cm}^{3} /\right. \\
\mathrm{mol})\end{array}$ \\
\hline Value & -0.0336 & 9.11 & -1161.3 & 4.6
\end{tabular}

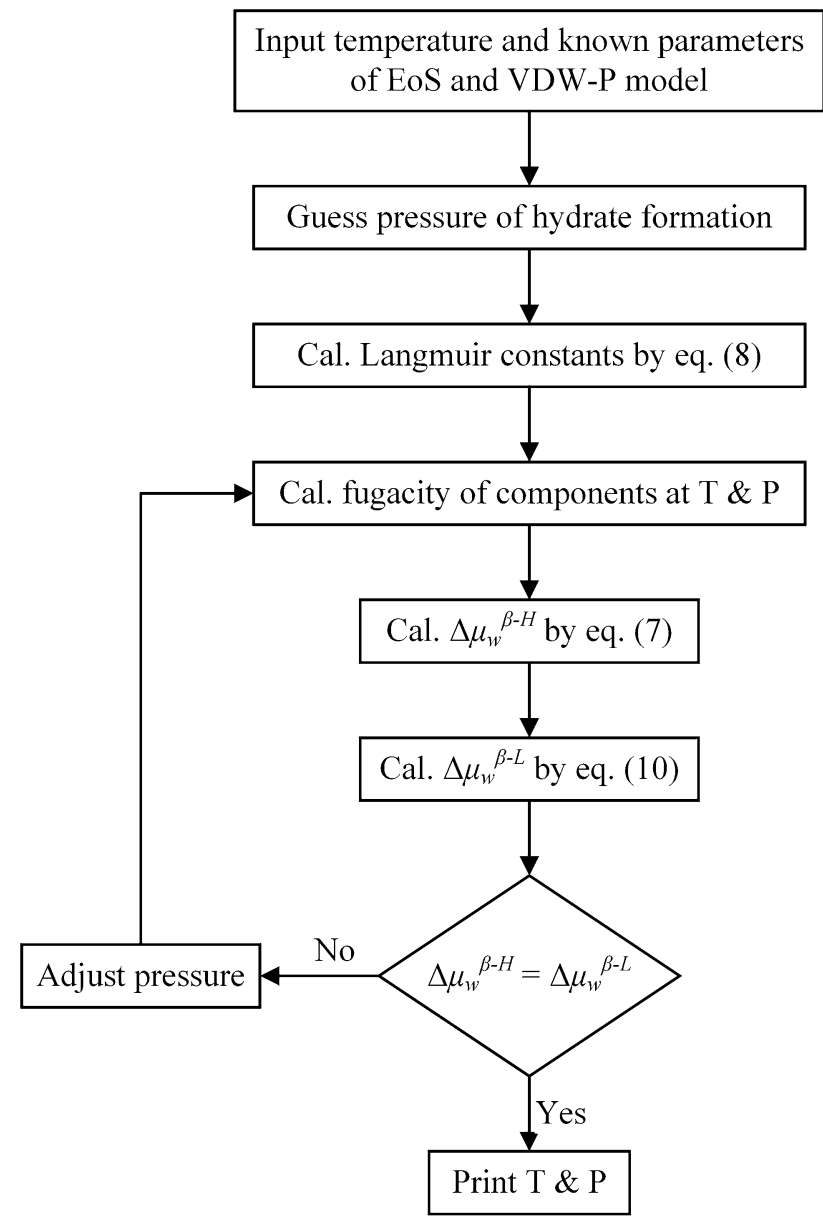

Fig. 1 Typical algorithm of VdW-P model

Also, heat capacity can be calculated as:

$\Delta C_{P}=\Delta C_{P}^{0}+\alpha^{\prime}\left(T-T_{0}\right)$

The required coefficients of above correlations are presented in Table 2 (Parrish and Prausnitz 1972).

The activity of water in liquid phase is presumed to be unit due to low solubility of methane in water. The calculation algorithm suggested by VdW-P model is shown in Fig. 1.

\section{Equation of state}

Six including cubic EOSs (van der Waals (VdW), Redlich-Kwong (RK), Soave-Redlich-Kwong (SRK) and Peng-Robinson (PR), Patel-Teja (PT) and Tsai-Jan (TJ))

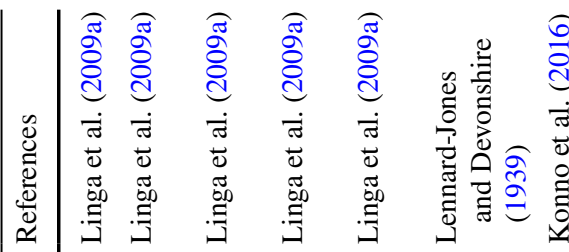

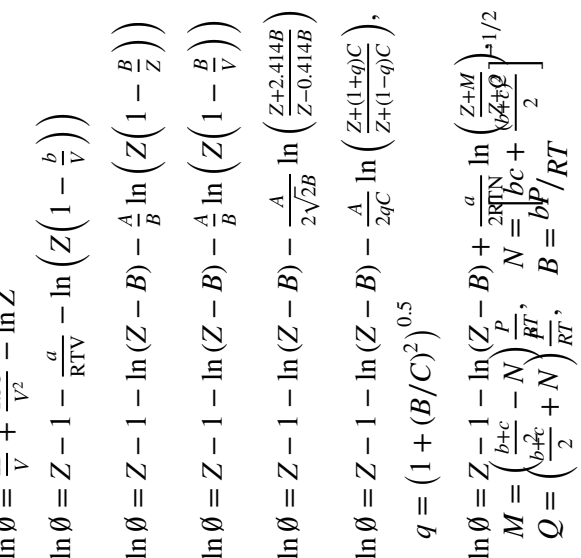

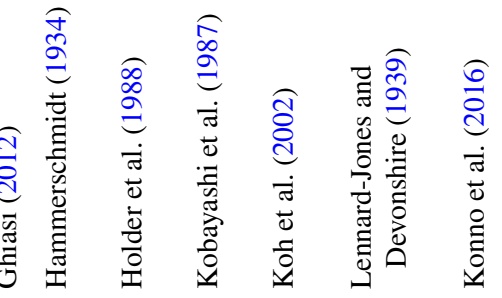

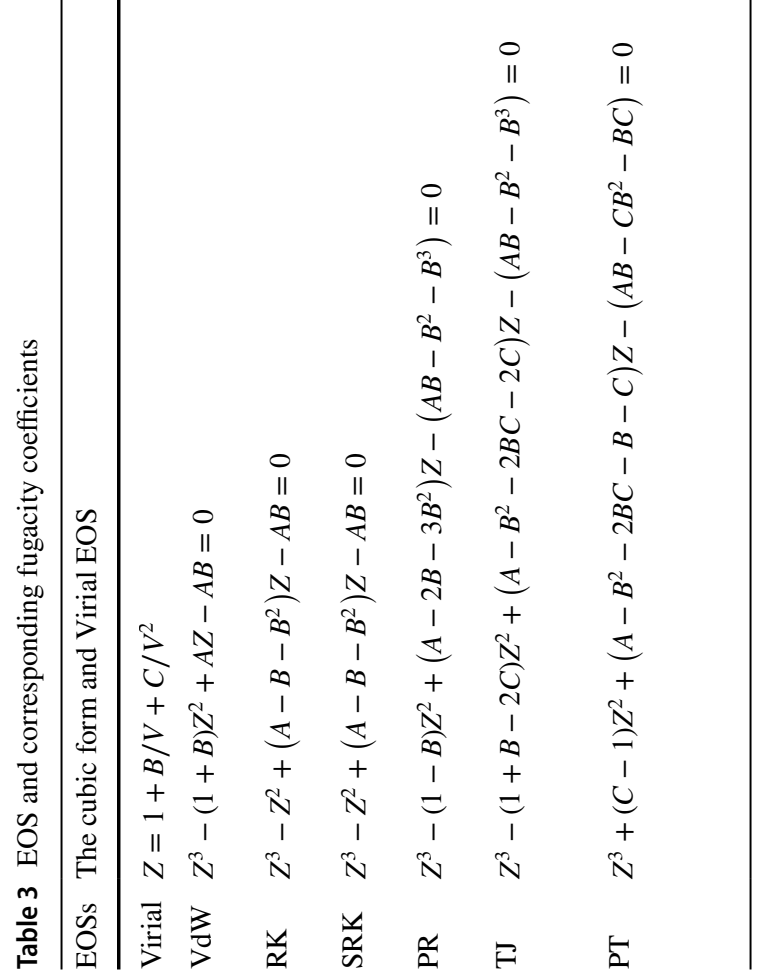


along with Virial EOS are introduced in Table 3. The corresponding fugacity coefficients of each EOS are shown in Table 3. These EOSs were chosen because of their popularity in equilibrium thermodynamic modeling. The fugacity coefficients are needed for calculation of pressure and temperature of hydrate formation.

\section{New correlation}

In this work, genetic programing (GP) is manipulated to develop new mathematical correlation for methane hydrate formation temperature (Ganji et al. 2007). The origin of evolutionary algorithms is Darwinian Theory which is inspired by biological evolution (Mohamadi-Baghmolaei et al. 2016a). These algorithms grow according to survival of fittest. The mutation and crossover process, which are the random mechanisms, introduce the strongest genomes as parents of next generations (Linga et al. 2009a). In GP algorithm, the individuals are represented by trees. Indeed, this method is capable of reproducing a mathematical equation based on its tree structural mechanism, whereas other evolutionary algorithms are incapable or their flexibility is less pronounced (Zhong et al. 2016). A tree structural GP individual is displayed in Fig. 2. The prefixed notion of GP presented equation (Fig. 2) is shown by Eq. (13).

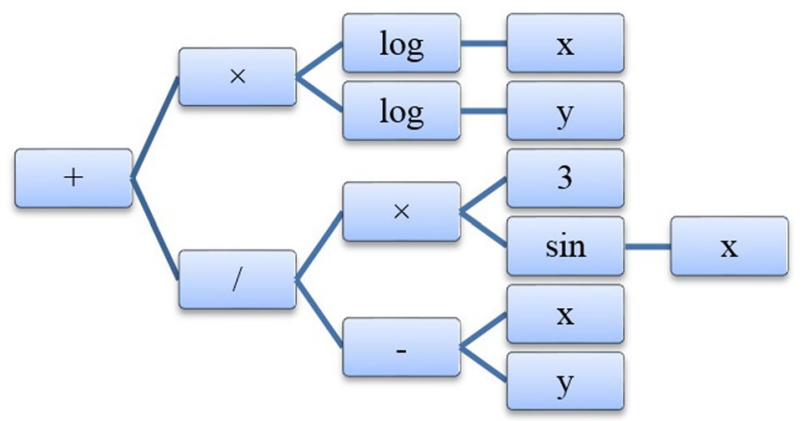

Fig. 2 Mutation process in GP
Parent $1=\log (x) \cdot \log (y)+\frac{y-x}{3 \sin (x)}$

The fundamental and detail concept of GP algorithm is described by Mohamadi-Baghmolaei et al. (2016b). Based on GP algorithm, a new correlation is developed to predict the hydrate formation temperature. The HFT $(\mathrm{K})$ is correlated for pure methane as function of pressure (MPa). About $75 \%$ of experimental data are implemented for validation of correlation, and the remains and non-repetitive data are chosen to test the new correlation. Tree structure of new correlation is shown in Fig. 3.

Details of proposed correlation are as follows:

$T=\boldsymbol{a}+\boldsymbol{b} \times \ln (A)$

$A=\boldsymbol{c} p+\boldsymbol{d} \times \ln (B)+\boldsymbol{e} \times \ln (p)-f / p$

$B=g \times \ln (p)$

The developed correlation covers a wide range existing input data $(259.1 \leq T(K) \leq 320.1)$ and compensates other correlations which are mostly coverless range of input data. Despite the long and tedious conventional empirical correlations, the new developed correlation includes less involving terms. The proposed correlation is simple, which makes it profitable for academic and industrial proposes. Constants of new correlation (Eqs. 14-16) are given in Table 4.

Table 4 Constants of new correlation

\begin{tabular}{ll}
\hline Coeff. & Value \\
\hline$a$ & 248.1 \\
$b$ & 11.26 \\
$c$ & 1.448 \\
$d$ & 2.305 \\
$e$ & 4.753 \\
$f$ & 3.636 \\
$g$ & 2 \\
\hline
\end{tabular}

Fig. 3 Tree structure of new correlation

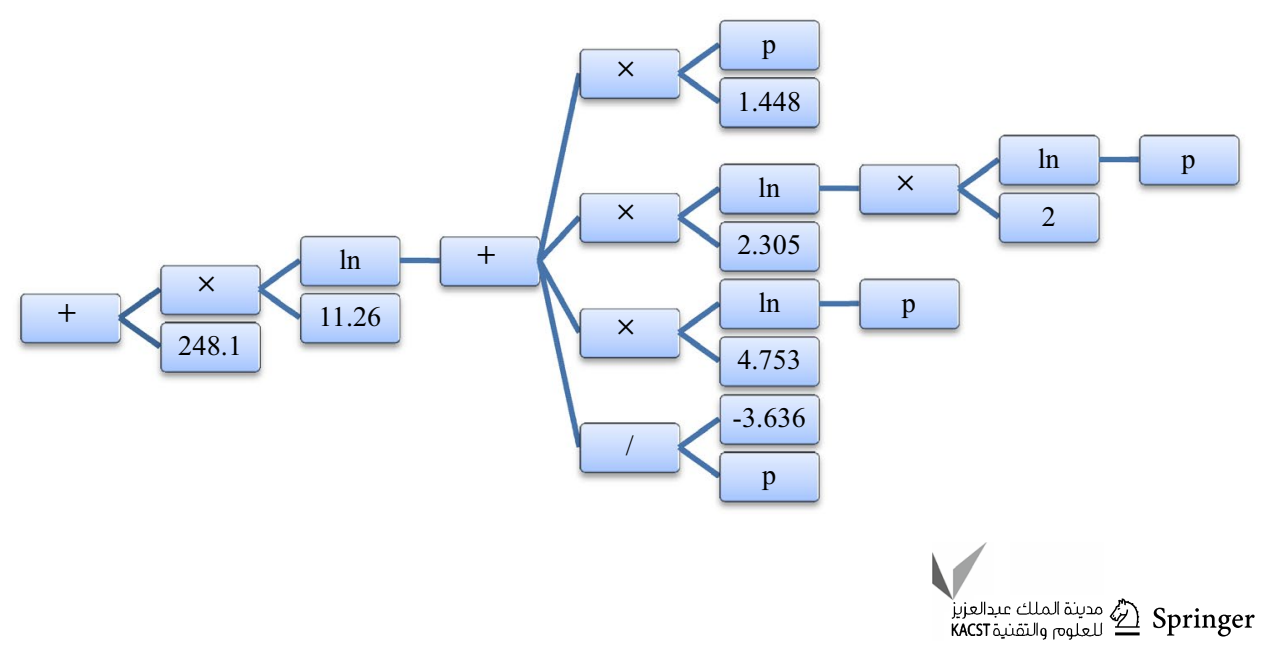


Table 5 Statistical information of data points

\begin{tabular}{lclcl}
\hline Property & Min. & Max. & Avg. & SD* \\
\hline Temperature (K) & 259.1 & 320.1 & 286.9 & 12.67 \\
Pressure (MPa) & 1.65 & 397 & 37.17 & 76.94 \\
\hline
\end{tabular}

*Standard deviation

\section{Results and discussion}

In this study, VdW-P thermodynamic model (considering seven EOSs) and several empirical correlations are chosen to find the most accurate one. To do this, 101 experimental datasets for pure methane were extracted from open literature (Sloan and Koh 2007). The statistical characteristics of data are reported in Table 5. Different statistical errors functions are used to evaluate models and determine the most accurate one. These functions are defined in "Required parameters of EOS" appendix section.

\section{Comparison of applying different EOSs in VdW-P model}

Quantitative comparison of utilizing different EOSs in VdW-P model based on statistical errors is presented in Table 6 where the temperature range is 259.1-320.1 (K). It is observed that for the total temperature range, the SRK EOS has the least and preferable root-mean-squared error (RMSE) (41.1626). In contrast, PR has the maximum value RMSE (1.2987e+04) which may make it unsuitable for prediction of hydrate formation condition. It is worth mentioning that for the temperature range of 259.1-284.3 (K), the Virial EOS is the most precise EOS with respect to statistical errors reported in Table 5. On the other hand, at temperatures higher than 284.3-320.1 K the SRK EOS is suggested to be used in VdW-P (see Table 6).

The accuracy of EOS in VdW-P model can be recognized from Figs. 4 and 5 where predicted pressures and experimental data are displayed by different symbols.

The Langmuir constants were determined based on SRK EOS, which has best predictions for HFP of methane. The
Table 6 Statistical error of HFP using EOS

Fig. 4 Comparison between different EOSs used in VdW-P for $259.1 \leq T \leq 284.3 \mathrm{~K}$

\begin{tabular}{|c|c|c|c|c|c|c|c|c|c|}
\hline \multirow[t]{2}{*}{ EOSs } & \multicolumn{3}{|c|}{$T \leq 284.3$} & \multicolumn{3}{|c|}{$284.3 \leq T$} & \multicolumn{3}{|c|}{$259.1 \leq T \leq 320.1$} \\
\hline & $R^{2}$ & RMSE & $\overline{\text { AARE }}$ & $R^{2}$ & RMSE & AARE & $\overline{R^{2}}$ & RMSE & AARE \\
\hline Virial & 0.9880 & 0.0246 & 4.5495 & 0.5030 & $1.2209 \mathrm{e}+03$ & 12.6382 & 0.6324 & $1.2209 \mathrm{e}+03$ & 14.9818 \\
\hline RK & 0.9810 & 0.0429 & 5.9936 & 0.9776 & 73.2635 & 8.9240 & 0.9789 & 73.2851 & 11.9505 \\
\hline VdW & 0.9644 & 0.0896 & 7.7468 & 0.6235 & 417.5920 & 10.9393 & 0.6892 & 417.6372 & 14.8510 \\
\hline SRK & 0.9852 & 0.0320 & 5.2796 & 0.9859 & 41.1465 & 6.4350 & 0.9887 & 41.1626 & 9.1010 \\
\hline PR & 0.9771 & 0.0531 & 6.5240 & 0.5258 & $1.2987 \mathrm{e}+04$ & 32.2215 & 0.5274 & $1.2987 \mathrm{e}+04$ & 35.5159 \\
\hline TJ & 0.9859 & 0.0302 & 5.1345 & 0.9123 & 458.9166 & 10.8965 & 0.9155 & 458.9318 & 13.4891 \\
\hline PT & 0.9873 & 0.0266 & 4.7471 & 0.8632 & 911.7403 & 11.4415 & 0.8669 & 911.7537 & 13.8385 \\
\hline
\end{tabular}

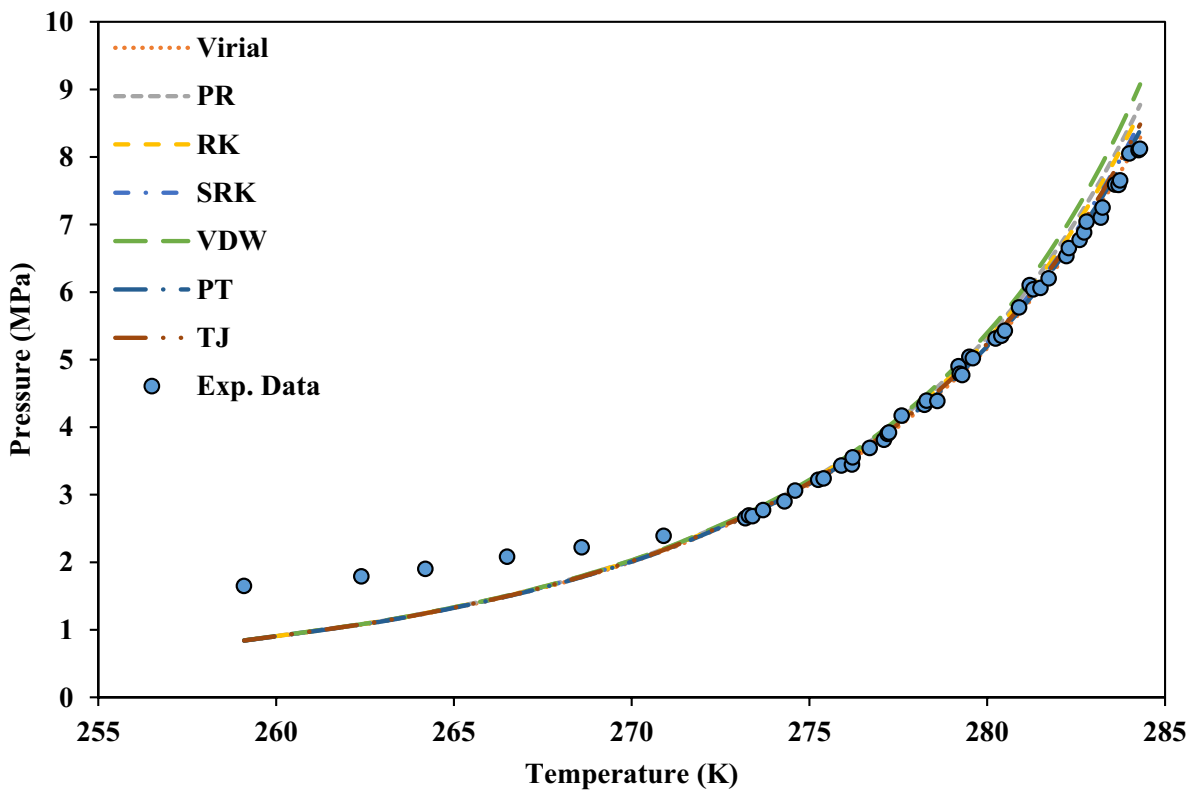


Fig. 5 Comparison between different EOSs used in VdW-P for $284.3 \leq T \leq 320.1 \mathrm{~K}$

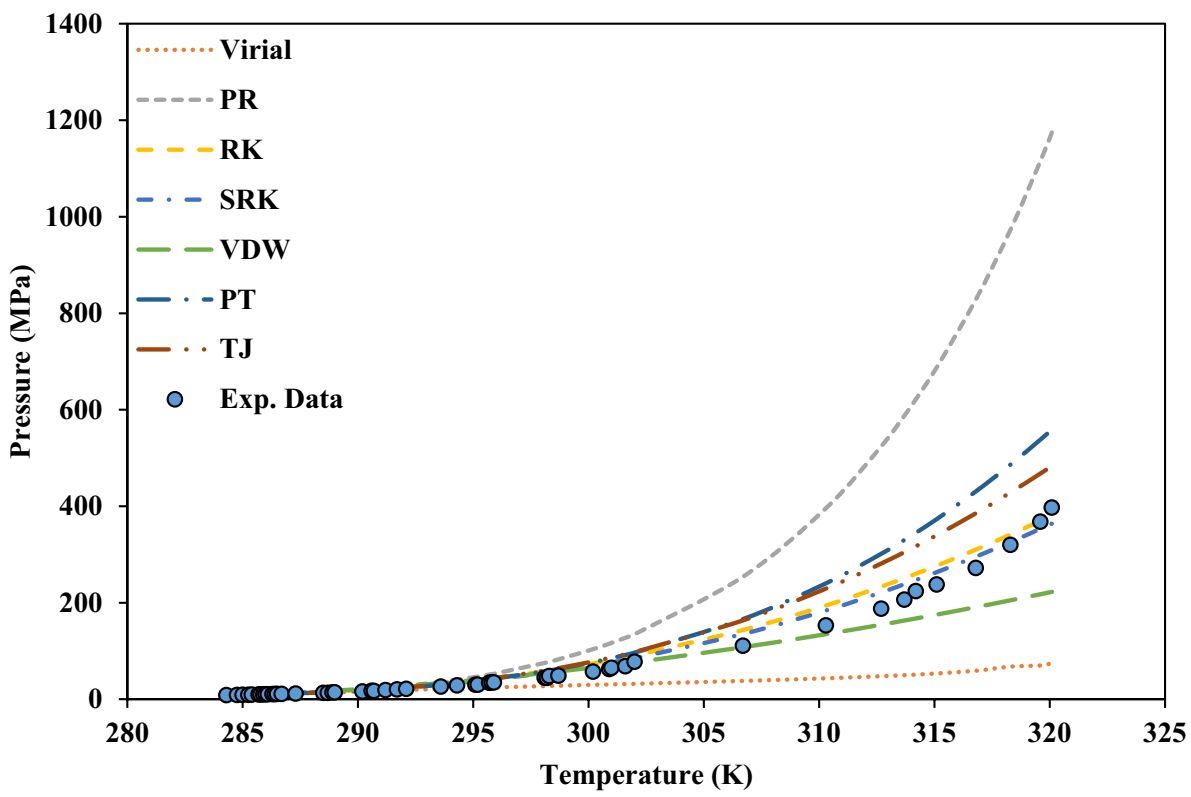

Table 7 Statistical errors of PR and Virial EOSs in comparison with SRK EOS

\begin{tabular}{lll}
\hline EOSs & RSS & AARE \\
\hline PR & 1.5420 & 0.3059 \\
Virial & 0.4477 & 0.2146 \\
\hline
\end{tabular}

Table 8 Statistical error of HFP using empirical correlations for $259.1 \leq T \leq 320.1$

\begin{tabular}{llrr}
\hline$S$ & $R^{2}$ & \multicolumn{1}{c}{ RMSE } & \multicolumn{1}{c}{ AARE } \\
\hline HSCH & 0.5683 & 129.9693 & 4.5487 \\
Berge & 0.9662 & 2.1431 & 0.3251 \\
Holder et al. & 0.4837 & 569.7024 & 16.4595 \\
BV & 0.2886 & 712.7525 & 11.8199 \\
Ghayyem et al. & 0.2989 & 431.9109 & 9.6792 \\
Ghiasi & 0.8478 & 6.7202 & 0.6999 \\
TM & 0.7354 & 19.6692 & 2.0549 \\
\hline
\end{tabular}

accuracy lays behind the difference between calculated fugacities by each EOS. Calculated errors of fugacity by different EOSs are shown in Table 7.

As mentioned before, accuracy of calculated fugacities should be evaluated and compared by the fugacities determined from SRK EOS in which the experimental pressure and temperature are applied. The results shown in Table 7 confirm that calculated fugacity by PR and Virial EOSs at experimental temperature and pressure are not consistent with SRK EOS at temperature higher than $295 \mathrm{~K}$; therefore, calculated HFP by these two EOSs has large statistical error.

\section{Comparison between empirical correlations}

Comparison between empirical correlations is given in Table 8. Of the seven correlations, the Berge has the least RMSE value (2.1431), followed by Ghiasi (Ghiasi 2012) with RMSE (6.7202). On the other side, Ghayyem et al. (2014) correlation shows a significant disagreement with experimental data. It should be mentioned that $\mathrm{HSCH}, \mathrm{BV}$, TM are the abbreviation form of Hammerschmidt (1934), Bahadori and Vuthaluru (2009), Towler and Mokhatab (2005) correlation, respectively. These correlations are introduced in "Empirical correlations" appendix section.

The accuracy of Berge correlation among others is clear in Fig. 6 where the high deviation of HSCH from experimental data is significantly apparent.

\section{Evaluation of new correlation}

The new developed correlation shows the highest agreement with experimental data, as shown in Table 9. The computed errors of developed correlation for validation and test steps are reported in Table 9.

Also, comparison between new correlation and experimental data is illustrated in Fig. 7. It is clear that the highest accuracy is observed in tracing experimental data using new correlation. As seen, total errors of proposed correlation compensate all reported empirical correlations and VdW-P models. The new correlation satisfied the experimental data well enough.

To compare best predicting method of HFP, scattered diagram of best empirical correlation, VdW-model and new correlation are depicted in Fig. 8. For temperature range of 259.1-284.3 K, the Virial EOS is the most accurate EOS. 
Fig. 6 Comparison between empirical correlations

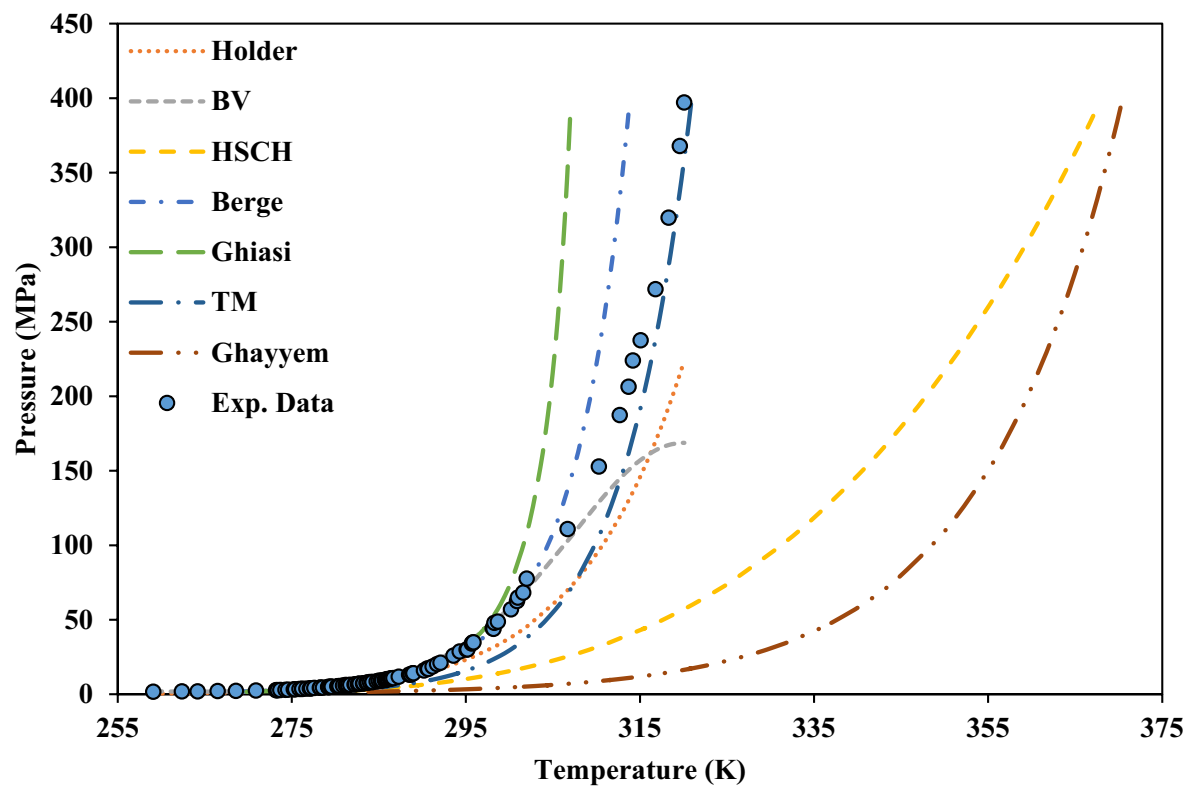

Table 9 Statistical error of HFP based on new correlation

\begin{tabular}{llll}
\hline New correlation & Train & Test & Overall \\
\hline$R^{2}$ & 0.9991 & 0.9987 & 0.9990 \\
RMSE & 0.0733 & 0.0970 & 0.0794 \\
AARE & 0.1056 & 0.1118 & 0.1072 \\
\hline
\end{tabular}

For overall temperature range (259.1-320.1 K), the SRK EOS has best results between other EOSs. In addition, Berge correlation is the most accurate one in comparison with other empirical correlations considering overall range of temperatures. Also, our new correlation is the best predictor between all other methods and equations.

\section{Modified correlations}

The modified HSCH correlation shows an improvement of predictability for HFP. It precedes all empirical correlation predictions. It is noteworthy that, the modified $\mathrm{HSCH}$ is more accurate than all models of VdW-P. Another modified correlation is that of Holder et al. although the modified Holder et al.'s correlation is better than the old version, but it is still less accurate in comparison with Berge and Ghiasi and TM correlations. The modified Holder et al.'s correlation convinces the experimental data much better than VdW-P models except for SRK EOS. The calculated errors for modified correlations are reported in Table 10. The modified correlations of $\mathrm{HSCH}$ and Holder et al. are:

$T=265.9744 P^{0.0309}$
Fig. 7 Comparison between new correlation and experimental data

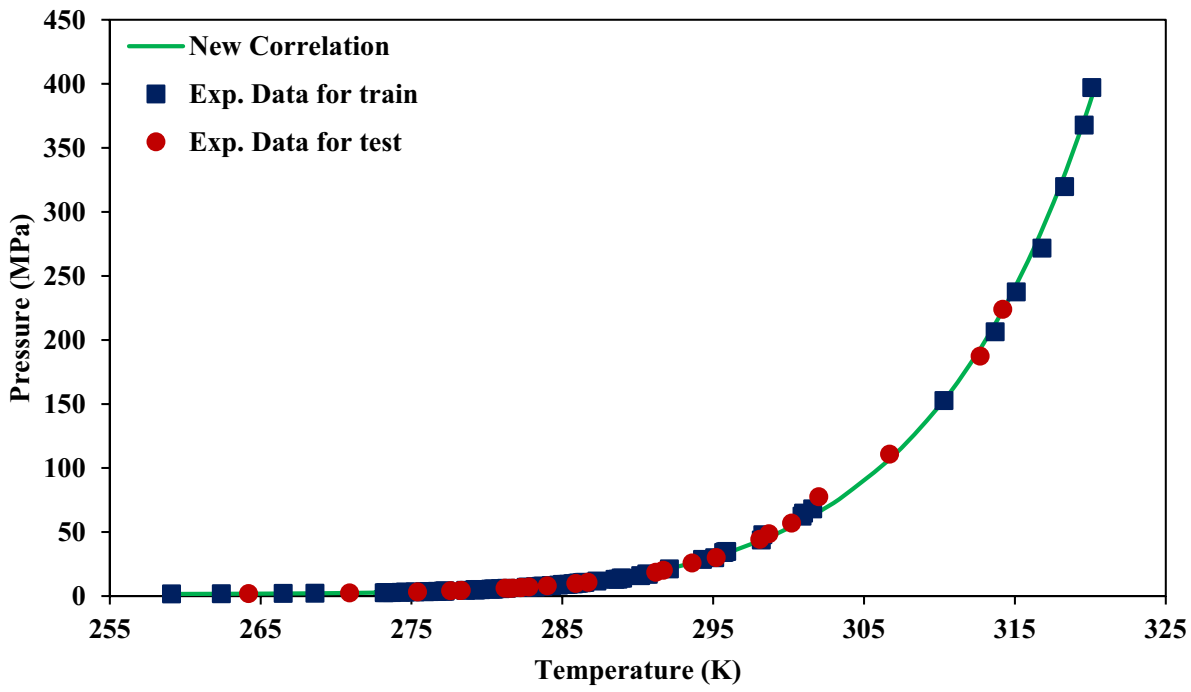


Fig. 8 Scattered diagrams of the best predicting methods
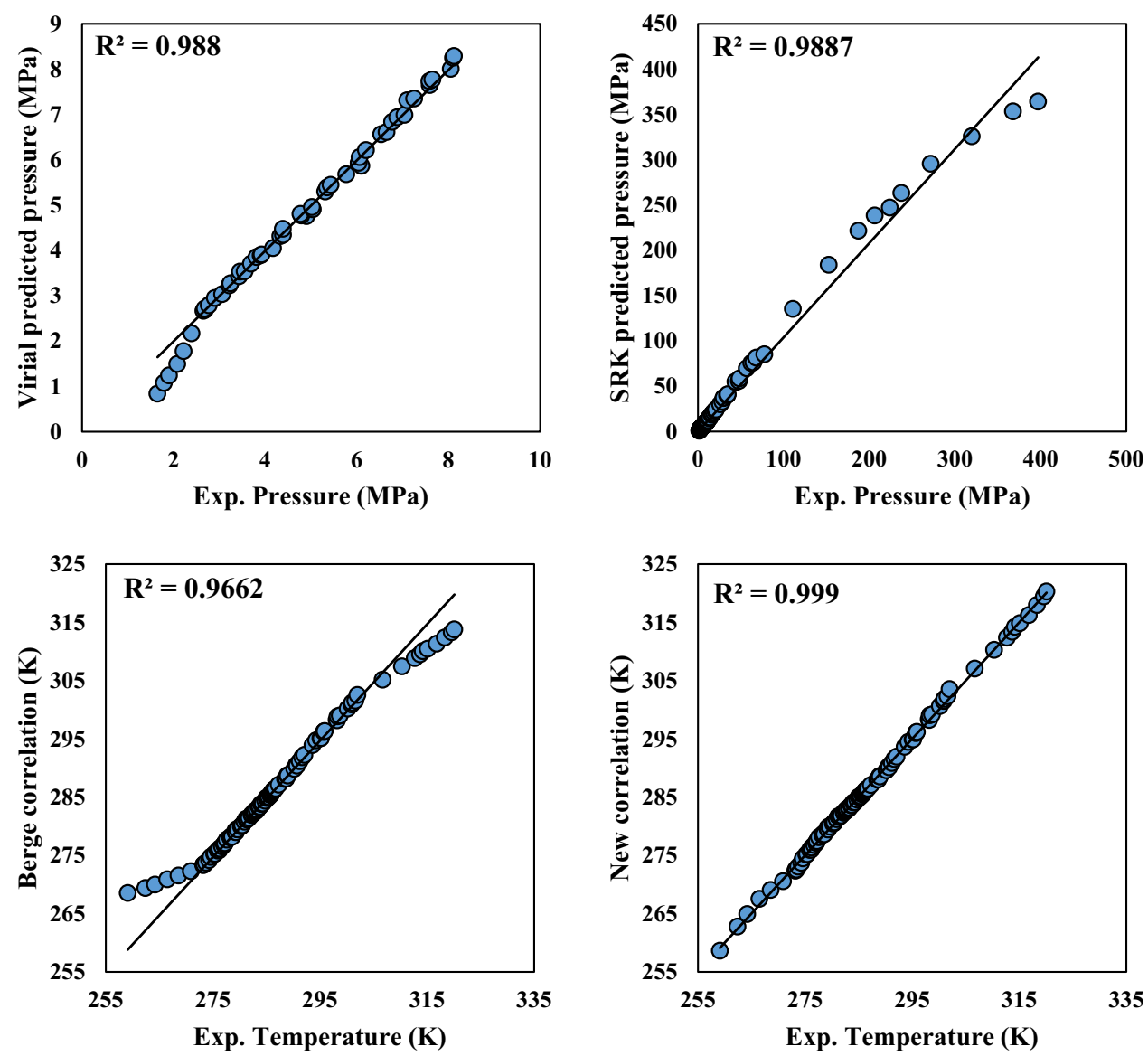

Table 10 Statistical error of HFP using modified empirical correlations

\begin{tabular}{llrr}
\hline Empirical correlation & $R^{2}$ & \multicolumn{1}{c}{ RMSE } & \multicolumn{1}{c}{ AARE } \\
\hline Mod * HSCH & 0.9777 & 1.6335 & 0.2998 \\
Mod holder & 0.9563 & 90.6184 & 10.0985 \\
\hline
\end{tabular}

*Mod denotes modified

$P=\exp \left(34.4077+\frac{-9165.9451}{T}\right)$

where temperature and pressure are reported in $\mathrm{K}$ and $\mathrm{MPa}$.

\section{Conclusion}

In the current paper, the new simple correlation for prediction of hydrate formation temperature for temperature range of 259.1-320.1 (K) was developed. The computed statistical errors signify the excellence of proposed method in comparison with common empirical correlations and application of different EOSs in VdW-P model. Also it has been noticed that for the range of $259.1 \leq T(\mathrm{~K}) \leq 284.3$ the Virial EOS is the best among other EOS, whereas for the temperature range of $284.3 \leq T(\mathrm{~K}) \leq 320.1$ the SRK EOS has the maximum consistency with experimental data. Of the seven empirical correlations, that of Berge is the most truthful. The simplicity and accuracy of proposed new correlation prepare the easiest way of methane HFT prediction among longsome VdW-P methods and complicated correlations.

Open Access This article is distributed under the terms of the Creative Commons Attribution 4.0 International License (http://creativecommons.org/licenses/by/4.0/), which permits unrestricted use, distribution, and reproduction in any medium, provided you give appropriate credit to the original author(s) and the source, provide a link to the Creative Commons license, and indicate if changes were made. 


\section{Appendix 1: Empirical correlations}

Berge proposed another correlation by including the gas specific gravity (Berge 1986). This correlation is written in the form of Eqs. (19) and (20) for two ranges of specific gravity. For $0.555 \leq \gamma \leq 0.58$

$$
\begin{aligned}
T= & \left(-96.03+25.37 \ln (P)-0.64 \ln (P)^{2}+\frac{(\gamma-0.555)}{0.025}\right) \\
& \times\left(80.61 P+\frac{1.16 \times 10^{4}}{P+599.16}-96.03+25.37 \ln (P)-0.64 \ln (P)^{2}\right)
\end{aligned}
$$

For $0.58 \leq \gamma \leq 1$

$T=\frac{-1.23 \times 10^{4}+80.61 P-2.1 \times 10^{4}-\frac{1.22 \times 10^{3}}{\gamma-0.535}-\frac{1.71 \times 10^{3}}{\gamma-0.509}}{\left(P-260.42-\frac{15.18}{\gamma-0.535}\right)}$

where the temperature and pressure are in ${ }^{\circ} \mathrm{F}$ and psi, respectively.Motiee offered a correlation as function of pressure $(\mathrm{kPa})$ and gas gravity for prediction of $\operatorname{HFT}\left({ }^{\circ} \mathrm{C}\right)(1991)$.

$$
\begin{aligned}
T= & -283.24469+78.99667 \log P \\
& -5.352544(\log P)^{2}+349.473877 \times \gamma \\
& -150.854675 \times \gamma^{2}-27.604065 \times \gamma \log (P)
\end{aligned}
$$

Another correlation for prediction of HFT was introduced by Towler and Mokhatab (TM) (2005).

$T=13.47 \ln P+34.27 \ln \gamma-1.675 \ln P \times \ln \gamma-20.35$

Bahadori and Vuthaluru (BV) presented specific equations for prediction of temperature and pressure of hydrate formation as function of molecular weight (2009).

$$
\begin{aligned}
& T=\exp \left(a+\frac{b}{P}+\frac{c}{P^{2}}+\frac{d}{P^{3}}\right) \\
& P=\exp \left(a+\frac{b}{T}+\frac{c}{T^{2}}+\frac{d}{T^{3}}\right)
\end{aligned}
$$

where $P$ and $T$ are in $\mathrm{kPa}$ and $\mathrm{K}$. The required parameters of Eqs. (23) and (24) are listed below:

$$
\begin{aligned}
& a=A_{1}+B_{1} M_{\mathrm{w}}+C_{1} M_{\mathrm{w}}^{2}+D_{1} M_{\mathrm{w}}^{3} \\
& b=A_{2}+B_{2} M_{\mathrm{w}}+C_{2} M_{\mathrm{w}}^{2}+D_{2} M_{\mathrm{w}}^{3} \\
& c=A_{3}+B_{3} M_{\mathrm{w}}+C_{3} M_{\mathrm{w}}^{2}+D_{3} M_{\mathrm{w}}^{3} \\
& d=A_{4}+B_{4} M_{\mathrm{w}}+C_{4} M_{\mathrm{w}}^{2}+D_{4} M_{\mathrm{w}}^{3}
\end{aligned}
$$

The above coefficients are reported by Bahadori and Vuthaluru.
Gheyyem et al. introduced an empirical correlation based on regression method. Their correlation was function of pressure (psi) and gas gravity to give HFT in ${ }^{\circ} \mathrm{F}$.

$T=a+\frac{b}{\gamma}+c \ln P+d \exp \left(\gamma^{g}\right)+e \ln (P)^{2}+f \ln (P) \times \exp \left(\gamma^{h}\right)$

The coefficients of Ghayyem correlation have been reported in his paper (Ghayyem et al. 2014).

\section{Appendix 2: Required parameters of EOS}

The needed parameters for cubic EOS form are presented in Tables 11, 12 and 13.

Where $\alpha$, for SRK and PR EOS, are presented by Eqs. (30) and (31), respectively:

$\alpha=\left(1+\left(0.48508+1.55171 \omega-0.15613 \omega^{2}\right)\left(1-{\frac{T}{T_{c}}}^{0.5}\right)\right)^{2}$

$\alpha=\left(1+\left(0.37464+1.54226 \omega-0.26992 \omega^{2}\right)\left(1-{\frac{T}{T_{c}}}^{0.5}\right)\right)^{2}$

$\Omega_{b}^{3}+\left(1-3 \zeta_{c}\right) \Omega_{b}^{2}+\left(1-3 \zeta_{c}+3 \zeta_{c}^{2}\right) \Omega_{b}-\zeta_{c}^{3}=0$

$\Omega_{a}=\Omega_{b}^{2}+\Omega_{b}+\zeta_{c}^{3} / \Omega_{b}$

$\Omega_{c}=\left(\Omega_{b}-3 \zeta_{c}+1\right) / 2$

$\zeta_{c}=0.32011-0.04539 \omega+0.01631 \omega^{2}$

$\alpha=\left(1+m\left(1-T_{r}^{0.5}\right)\right)^{2}$

$m=m_{0}+\left(4 T_{r}-m_{0}-2\right)^{2} / 50$ for $T_{r} \leq 1$

$m=m_{0}+\left(2-m_{0}\right)^{2} / 50$ for $T_{r}>1$

$m_{0}=0.375+1.546 \omega-0.292 \omega^{2}$

Table 11 VdW, RK, SRK, and PR EOS parameters

\begin{tabular}{llllll}
\hline EOSs & $A$ & $B$ & $a$ & $b$ & References \\
\hline VdW & $\frac{a P}{R^{2} T^{2}}$ & $\frac{b P}{R T}$ & $0.421875 \frac{R^{2} T_{c}^{2}}{P_{c}}$ & $0.125 \frac{R T_{c}}{P_{c}}$ & Linga et al. (2009a) \\
RK & $\frac{a p}{R^{2} T^{2.5}}$ & $\frac{b p}{R T}$ & $0.42747 \frac{R^{2} T_{c}^{2.5}}{p_{c}}$ & $0.08664 \frac{R T_{c}}{p_{c}}$ & Linga et al. (2009a) \\
SRK & $\frac{a \alpha p}{R^{2} T^{2}}$ & $\frac{b p}{R T}$ & $0.42747 \frac{R^{2} T_{c}^{2.5}}{p_{c}}$ & $0.08664 \frac{R T_{c}}{p_{c}}$ & Linga et al. (2009a) \\
PR & $\frac{a \alpha p}{R^{2} T^{2}}$ & $\frac{b p}{R T}$ & $0.457235 \frac{R^{2} T_{c}^{2}}{P_{c}}$ & $0.077796 \frac{R T_{c}}{p_{c}}$ & Linga et al. (2009a)
\end{tabular}


Table 12 TJ EOS parameters

\begin{tabular}{lllllllll}
\hline EOS & $A$ & $B$ & $C$ & $a(\mathrm{~T})$ & $a_{c}$ & $b$ & $c$ & Reference \\
\hline TJ & $\frac{a(T) . P}{R^{2} T^{2}}$ & $\frac{b P}{R T}$ & $\frac{c P}{R T}$ & $a_{c} \cdot \alpha(T)$ & $\Omega_{a}\left(R^{2} T_{c}^{2} / P_{c}\right)$ & $\Omega_{b}\left(R T_{c} / P_{c}\right)$ & $\Omega_{c}\left(R T_{c} / P_{c}\right)$ & Lennard-Jones and Devonshire (1939) \\
\hline
\end{tabular}

Table 13 PT EOS parameters

\begin{tabular}{lllllllll}
\hline EOS & $A$ & $B$ & $C$ & $a(\mathrm{~T})$ & $a_{c}$ & $b$ & $c$ & Reference \\
\hline $\mathrm{PT}$ & $\frac{a(T) . P}{R^{2} T^{2}}$ & $\frac{b P}{R T}$ & $\frac{c P}{R T}$ & $a_{c} \cdot \alpha(T)$ & $\Omega_{a}\left(R^{2} T_{c}^{2} / P_{c}\right)$ & $\Omega_{b}\left(R T_{c} / P_{c}\right)$ & $\Omega_{c}\left(R T_{c} / P_{c}\right)$ & Konno et al. (2016) \\
\hline
\end{tabular}

$\Omega_{b}^{3}+\left(2-3 \zeta_{c}\right) \Omega_{b}^{2}+3 \zeta_{c}^{2} \Omega_{b}-\zeta_{c}^{3}=0$

$\Omega_{a}=3 \zeta_{c}^{2}+3\left(1-2 \zeta_{c}\right) \Omega_{b}+\Omega_{b}^{2}+1-3 \zeta_{c}$

$\Omega_{c}=1-\zeta_{c}$

$\zeta_{c}=0.329032-0.076799 \omega+0.0211947 \omega^{2}$

$\alpha=\left(1+F\left(1-T_{r}^{0.5}\right)\right)^{2}$

$F=0.452413+1.30982 \omega-0.295937 \omega^{2}$

\section{Appendix 3: Types of errors}

\section{Coefficient of determination}

$R^{2}=1-\frac{\sum_{i=1}^{N}\left(Z_{i}^{\text {Pred }}-Z_{i}^{\exp }\right)^{2}}{\sum_{i=1}^{N}\left(Z_{i}^{\text {Pred }}-\operatorname{average}\left(Z_{i}^{\exp }\right)\right)^{2}}$

Average absolute relative error

$\operatorname{AARE} \%=\frac{100}{N} \sum_{i=1}^{N}\left(\left|\frac{Z_{i}^{\text {Pred }}-Z_{i}^{\text {exp }}}{Z_{i}^{\exp }}\right|\right)$

Root-mean-square error

$\operatorname{RMSE}=\left(\frac{\sum_{i=1}^{N}\left(Z_{i}^{\text {Pred }}-Z_{i}^{\exp }\right)^{2}}{N}\right)^{\frac{1}{2}}$

Residual sum of square

$\mathrm{RSS}=\sum_{i=1}^{N}\left(Z_{i}^{\text {Pred }}-Z_{i}^{\text {exp }}\right)^{2}$

\section{References}

Amin JS, Nikkhah S, Veiskarami M (2015) A statistical method for assessment of the existing correlations of hydrate forming conditions. J Energy Chem 24:93-100

Babu P, Kumar R, Linga P (2013) Pre-combustion capture of carbon dioxide in a fixed bed reactor using the clathrate hydrate process. Energy 50:364-373

Bahadori A, Vuthaluru HB (2009) A novel correlation for estimation of hydrate forming condition of natural gases. J Nat Gas Chem $18: 453-457$

Berge B (1986) Hydrate predictions on a microcomputer. Petroleum industry application of microcomputers. Society of Petroleum Engineers, Silvercreek, Colorado. https://doi. org/10.2118/15306-MS

Carroll J (2014) Natural gas hydrates: a guide for engineers. Gulf Professional Publishing, Houston

Chari VD, Sharma DV, Prasad PS, Murthy SR (2013) Methane hydrates formation and dissociation in nano silica suspension. $\mathrm{J}$ Nat Gas Sci Eng 11:7-11

Chen G-J, Guo T-M (1996) Thermodynamic modeling of hydrate formation based on new concepts. Fluid Phase Equilib 122:43-65

Collett TS (2002) Energy resource potential of natural gas hydrates. AAPG Bull 86:1971-1992

Collett TS, Boswell R, Cochran JR, Kumar P, Lall M, Mazumdar A, Ramana MV, Ramprasad T, Riedel M, Sain K (2014) Geologic implications of gas hydrates in the offshore of India: results of the national gas hydrate program expedition 01. Mar Pet Geol 58:3-28

Elgibaly AA, Elkamel AM (1998) A new correlation for predicting hydrate formation conditions for various gas mixtures and inhibitors. Fluid Phase Equilib 152:23-42

Fujii T, Suzuki K, Takayama T, Tamaki M, Komatsu Y, Konno Y, Yoneda J, Yamamoto K, Nagao J (2015) Geological setting and characterization of a methane hydrate reservoir distributed at the first offshore production test site on the Daini-Atsumi Knoll in the eastern Nankai Trough, Japan. Mar Pet Geol 66:310-322

Ganji H, Manteghian M, Omidkhah M, Mofrad HR (2007) Effect of different surfactants on methane hydrate formation rate, stability and storage capacity. Fuel 86:434-441

Garapati N, Anderson BJ (2014) Statistical thermodynamics model and empirical correlations for predicting mixed hydrate phase equilibria. Fluid Phase Equilib 373:20-28

Ghayyem M, Izadmehr M, Tavakoli R (2014) Developing a simple and accurate correlation for initial estimation of hydrate formation temperature of sweet natural gases using an eclectic approach. J Nat Gas Sci Eng 21:184-192

Ghiasi MM (2012) Initial estimation of hydrate formation temperature of sweet natural gases based on new empirical correlation. J Nat Gas Chem 21:508-512 
Hammerschmidt E (1934) Formation of gas hydrates in natural gas transmission lines. Ind Eng Chem 26:851-855

Holder G, Zetts S, Pradhan N (1988) Phase behavior in systems containing clathrate hydrates: a review. Rev Chem Eng 5:1-70

Kobayashi R, Song KY, Sloan ED (1987) Phase behavior of water/ hydrocarbon systems. Pet Eng Handb 25:e13

Koh C, Westacott R, Zhang W, Hirachand K, Creek J, Soper A (2002) Mechanisms of gas hydrate formation and inhibition. Fluid Phase Equilib 194:143-151

Konno Y, Masuda Y, Akamine K, Naiki M, Nagao J (2016) Sustainable gas production from methane hydrate reservoirs by the cyclic depressurization method. Energy Convers Manag 108:439-445

Lennard-Jones J, Devonshire A (1939) Critical and co-operative phenomena. IV. A theory of disorder in solids and liquids and the process of melting. In: Proceedings of the Royal Society of London. Series A, mathematical and physical sciences, pp 464-484

Liang M, Chen G, Sun C, Yan L, Liu J, Ma Q (2005) Experimental and modeling study on decomposition kinetics of methane hydrates in different media. J Phys Chem B 109:19034-19041

Lim SH, Riffat SB, Park SS, Oh SJ, Chun W, Kim NJ (2014) Enhancement of methane hydrate formation using a mixture of tetrahydrofuran and oxidized multi-wall carbon nanotubes. Int J Energy Res 38:374-379

Linga P, Haligva C, Nam SC, Ripmeester JA, Englezos P (2009a) Gas hydrate formation in a variable volume bed of silica sand particles. Energy Fuels 23:5496-5507

Linga P, Haligva C, Nam SC, Ripmeester JA, Englezos P (2009b) Recovery of methane from hydrate formed in a variable volume bed of silica sand particles. Energy Fuels 23:5508-5516

Mohamadi-Baghmolaei M, Mahmoudy M, Jafari D, MohamadiBaghmolaei R, Tabkhi F (2014) Assessing and optimization of pipeline system performance using intelligent systems. J Nat Gas Sci Eng 18:64-76

Mohamadi-Baghmolaei M, Azin R, Osfuri S, Mohamadi-Baghmolaei R, Zarei Z (2015) Prediction of gas compressibility factor using intelligent models. Nat Gas Ind B 2:283-294

Mohamadi-Baghmolaei M, Azin R, Sakhaei Z, Mohamadi-Baghmolaei $\mathrm{R}$, Osfouri S (2016a) Novel method for estimation of gas/oil relative permeabilities. J Mol Liq 223:1185-1191

Mohamadi-Baghmolaei M, Azin R, Zarei Z, Osfouri S (2016b) Presenting decision tree for best mixing rules and Z-factor correlations and introducing novel correlation for binary mixtures. Petroleum 2:289-295

Motiee M (1991) Estimate possibility of hydrates. Hydrocarb Process 70:98-99

Park SS, Kim NJ (2010) Multi-walled carbon nano tubes effects for methane hydrate formation. In: 2010 the 2 nd international conference on computer and automation engineering (ICCAE), IEEE

Parrish WR, Prausnitz JM (1972) Dissociation pressures of gas hydrates formed by gas mixtures. Ind Eng Chem Process Des Dev 11:26-35

Pasieka J, Coulombe S, Servio P (2013) Investigating the effects of hydrophobic and hydrophilic multi-wall carbon nanotubes on methane hydrate growth kinetics. Chem Eng Sci 104:998-1002

Patel NC, Teja AS (1982) A new cubic equation of state for fluids and fluid mixtures. Chem Eng Sci 37:463-473
Peng D-Y, Robinson DB (1976) A new two-constant equation of state. Ind Eng Chem Fundam 15:59-64

Prausnitz JM, Lichtenthaler RN, deAzevedo EG (1998) Molecular thermodynamics of fluid-phase equilibria. Pearson Education, London

Redlich O, Kwong JN (1949) On the thermodynamics of solutions. V. An equation of state. Fugacities of gaseous solutions. Chemical reviews 44:233-244

Ruppel C, Boswell R, Jones E (2008) Scientific results from Gulf of Mexico gas hydrates Joint Industry Project Leg 1 drilling: introduction and overview. Mar Pet Geol 25:819-829

Ryu B-J, Collett TS, Riedel M, Kim GY, Chun J-H, Bahk J-J, Lee JY, Kim J-H, Yoo D-G (2013) Scientific results of the second gas hydrate drilling expedition in the Ulleung basin (UBGH2). Mar Pet Geol 47:1-20

Siangsai A, Rangsunvigit P, Kitiyanan B, Kulprathipanja S (2014) Improved methane hydrate formation rate using treated activated carbon and tetrahydrofuran. J Chem Eng Jpn 47:352-357

Siangsai A, Rangsunvigit P, Kitiyanan B, Kulprathipanja S, Linga P (2015) Investigation on the roles of activated carbon particle sizes on methane hydrate formation and dissociation. Chem Eng Sci 126:383-389

Sloan ED Jr, Koh C (2007) Clathrate hydrates of natural gases. CRC Press, Boca Raton

Soave G (1972) Equilibrium constants from a modified Redlich-Kwong equation of state. Chem Eng Sci 27:1197-1203

Towler B, Mokhatab S (2005) Quickly estimate hydrate formation conditions in natural gases. Hydrocarb Process 84:61-62

Tsai FN, Jan DS (1990) A three-parameter cubic equation of state for fluids and fluid mixtures. Can J Chem Eng 68:479-486

Van der Waals JD (1873) Over de continuiteit van den gas-en vloeistoftoestand. AW Sijthoff, Leiden

Van der Waals J, Platteeuw J (2007) Clathrate solutions. Adv Chem Phys 2:1-57

Vedachalam N, Srinivasalu S, Rajendran G, Ramadass G, Atmanand M (2015) Review of unconventional hydrocarbon resources in major energy consuming countries and efforts in realizing natural gas hydrates as a future source of energy. J Nat Gas Sci Eng 26:163-175

Wilcox WI, Carson D, Katz D (1941) Natural gas hydrates. Ind Eng Chem 33:662-665

Yan L, Chen G, Pang W, Liu J (2005) Experimental and modeling study on hydrate formation in wet activated carbon. J Phys Chem B 109:6025-6030

Zhong D-L, Li Z, Lu Y-Y, Wang J-L, Yan J (2015) Evaluation of $\mathrm{CO}_{2}$ removal from a $\mathrm{CO}_{2}+\mathrm{CH}_{4}$ gas mixture using gas hydrate formation in liquid water and THF solutions. Appl Energy 158:133-141

Zhong D-L, Ding K, Lu Y-Y, Yan J, Zhao W-L (2016) Methane recovery from coal mine gas using hydrate formation in water-in-oil emulsions. Appl Energy 162:1619-1626

Publisher's Note Springer Nature remains neutral with regard to jurisdictional claims in published maps and institutional affiliations. 